\title{
HISTÒRIA, MATEMÀTIQUES I REALITAT
}

\author{
Lourdes Figueiras Ocaña i Jordi Deulofeu Piquet. Àrea de Didàctica de la Matemàtica. \\ Universitat Autònoma de Barcelona
}

Comptar i mesurar són dues de les activitats humanes que més freqüentment s'associen a les matemàtiques, i és ben cert que no podríem aproximar-nos a la història d'aquesta ciència sense referir-nos, en algun moment, a qualsevol d'elles. Els manuals que volen presentar el desenvolupament de les matemàtiques des del seu començament troben el punt de partida en aquestes activitats, perquè comptar i mesurar acompanyen una història de necessitats $i$ inquietuds humanes fonamentades en el treball agrícola, en les transaccions comercials, en les guerres o en el poder d'uns sobre els altres. Per als primers homes i dones era suficient amb distingir $u$ i dos de molts, de la mateixa manera que ho fan els nens i nenes durant els seus primers anys de vida. Moltes de les activitats per a les quals nosaltres necessitem la bastida complexa i ben estructurada dels sistemes de numeració es duen a terme utilitzant diferents tipus d'estratègies: osques damunt una fusta, apilament de còdols o de cargols de mar, etc. De la mateixa manera la mesura, tal i com l'entenem en el llenguatge actual, ha estat present al llarg de la història: homes i dones ajustaven la mida de la corda a l'arc, calculaven distàncies amb els seus pams 0 amb l'abast del pas dels animals de llaurar i fabricaven utensilis procurant ajustar les seves dimensions a necessitats diferents.

Un preàmbul d'aquesta mena sembla suggerir una matemàtica viva en la història dels pobles, al servei de les necessitats humanes i en estreta relació amb la cultura. D'on ve, doncs, la seva imatge popular en el sentit que és una ciència distant, que no té la calidesa que transmeten altres ciències humanes? Potser hi ha dues matemàtiques? Per què un llibre de text que a la seva introducció comença parlant d'homes i dones que mesuren un camp al pas dels bous continua immediatament amb abstraccions difícils de comprendre? Per a què serveixen, finalment, les matemàtiques que s'aprenen a l'escola?

La recerca de respostes a aquest tipus de preguntes és la que impulsa la redacció d'aquest article. Des del nostre punt de vista, no és interessant per a la cultura matemàtica de la nostra societat, i en particular per a l'educació de nois i noies en edat escolar, transmetre posicions extremes al voltant de la naturalesa de l'activitat matemàtica, que la majoria de les vegades van implícites en la nostra forma de parlar i d'actuar. En particular, tan poc beneficiosa és per a l'educació una imatge exclusivament axiomàtica i teòrica de la matemàtica com una altra que defensi que es tracta d'una ciència universalment aplicable i útil a la nostra activitat diària. La primera, perquè sovint genera rebuig i incomprensió; i la segona, perquè limita i empobreix una activitat humana que fa referència al plaer de pensar en objectes matemàtics i de crear-ne altres de nous des d'una perspectiva lògica. Trobar bellesa o utilitat tècnica en l'activitat matemàtica no ha d'ésser, en cap cas, un imperatiu, ni per als mestres ni per als alumnes. L'interessant, abans que res, és el fet de tenir la possibilitat de decidir si les matemàtiques ens semblen belles 0 no, i per això el més adient és aproximar-s'hi obertament; mirar-les des de perspectives diferents; descobrir la seva estètica particular; fer l'esforç de comprendre què hi ha darrere de cada problema i assumir la responsabilitat de parlar d'elles amb el rigor i la serenitat que exigeix qualsevol tasca educativa.

\section{Matemàtiques, en quin context?}

Al llarg d'anys d'experiència amb estudiants de magisteri, hem trobat que la imatge més generalitzada sobre què és la matemàtica, en el moment que comencen la seva carrera universitària, és estrictament i bàsicament la d'una matèria escolar. D'aquesta percepció es desprèn un sentit molt primari de l'aplicació: la matemàtica és útil per a moure's amb habilitat en situacions com anar a comprar, canviar divises, prendre mesures o fer un moble, i així ho transmetran en general als nens i nenes quan exerceixin de mestres. Es tracta d'un sentit directament relacionat amb els coneixements matemàtics tradicionals de l'ensenyament primari. En aquesta etapa, situacions quotidianes com les mencionades-comprar, prendre mesures, etc.- pot ser que resultin suficientment significatives pel nivell de conceptualització matemàtica que la majoria de les nostres escoles ofereixen als nens i nenes, però a mesura que aquests nens i nenes maduren, la seva vida quotidiana creix en complexitat. Es produeix una separació entre l'activitat intel-lectual desenvolupada i les matemàtiques que aprenen, de manera que no s'amplia el sentit que fins aleshores 


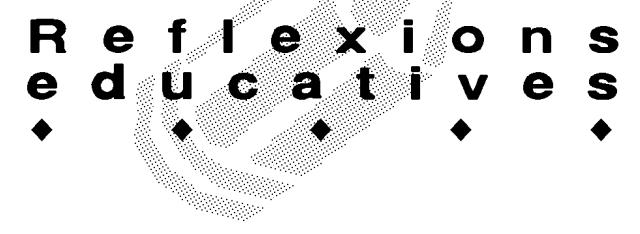

podien atorgar a aquesta ciència, i, per tant, s'empobreix. Les matemàtiques se separen de la vida quotidiana i el sentit de la utilitat, únicament referit a les activitats bàsiques de comprar, fer comptes, etc., queda estancat i es converteix en un tòpic. Així doncs, quan les idees i conceptes amb els quals s'enfronten els estudiants es tornen, matemàticament parlant, més complexos, -diguem que als últims cursos d'educació primària i durant tota l'educació secundària- la imatge de la matemàtica que es genera és la d'un conjunt de tècniques aïllades que s'aprenen a l'escola, i que no se sap gaire bé per a què serveixen. D'aquí que molts estudiants es refereixin a la matemàtica no a partir d'idees, sinó de paraules que evoquen conceptes o tècniques (fer matemàtiques és fer comptes, operar amb fraccions i potències, calcular el mínim comú múltiple, resoldre equacions, etc.).

És cert que durant molts anys un dels grans esforços de l'educació matemàtica ha estat el de mostrar la seva aplicabilitat a l'entorn quotidià dels estudiants de qualsevol nivell. Fa uns anys, aquest objectiu es va imposar com un repte, tant pel que fa a acostar les matemàtiques a la vida quotidiana com per fer més amigable una matèria que fins al moment transmetia el formalisme d'un llenguatge aliè. D'aquí ve, per exemple, que un indicador de la qualitat dels problemes -que encara es manté- és que el seu enunciat sigui contextualitzat a la realitat dels estudiants. Però, què significa realment que un enunciat o una pràctica matemàtica estiguin contextualitzats?

Si s'analitza amb ull crític, bona part dels contextos que evoquen els problemes que plantegem als nens $\mathrm{i}$ nenes no són reals, només ho semblen. Per altra banda, molts altres, que tenen un important sentit històric 0 teòric, es consideren poc apropiats perquè usen, per exemple, unitats de mesura diferents de les que fem servir habitualment, situacions pròpies de la realitat d'altres cultures, o sistemes de numeració històrics. El problema és, per tant, que en l'intent d'acostar la matemàtica a la vida quotidiana pugui reduir-se el seu interès fins al punt que només s'hi doni cabuda a unes poques tècniques, que suposadament seran les que serviran als ciutadans per desenvolupar-se com a tals. És molt probable que al posar tant esforç per acostar a l'escola, unes matemàtiques de la vida quotidiana, s'obviïn les seves arrels culturals i històriques, o que l'únic sentit que s'atorgui a la matemàtica giri al voltant de les seves aplicacions en l'àmbit científic i tecnològic. Utilitzar i mostrar aplicacions de les matemàtiques és evidentment necessari, enriquidor i positiu, sempre que aquestes aplicacions no es trivialitzin, i d'aquest fet no es desprengui que la matemàtica només té sentit quan es pugui parlar de matemàtica aplicada. El plaer associat a l'esforç de l'activitat intel-lectual, la investigació i la creativitat a l'hora de resoldre problemes, a l'escola es passa per alt massa sovint.

Un bon exemple per a reflexionar sobre la importància de la contextualització dels problemes escolars, i que també té el seu interès des del punt de vista de la investigació educativa, és el que es coneix com a "problema de l'edat del capità", que s'ha convertit en un clàssic als estudis sobre psicologia de l'educació matemàtica: "En un vaixell hi ha 26 bens i 10 cabres. Quants anys té el seu capità?"

L'any 1980 es plantejà el problema a França a alumnes entre els 7 i els 9 anys, dins del marc d'una investigació psicològica, i s'observà que dels 97 estudiants que van respondre, 76 calcularen l'edat del capità a partir de les dades numèriques que hi havia a la pregunta $(26+10$, per exemple). A banda de les conclusions que es puguin extreure, el cert és que podria pensar-se que el sorprenent de la situació no és la resposta dels nens, sinó que se'ls faci perdre el temps amb aquests estudis. El problema, que es planteja amb el convenciment que es tracta d'un problema absurd, no ho seria si es tingués en compte el seu origen. Amb independència que a l'enunciat del problema es parli de cabres, bens o dimensions del vaixell, la realitat és que tenia sentit en una època prèvia a la de la invenció de la màquina de vapor, en la qual l'edat del capità es considerava un factor rellevant per avaluar el risc en la navegació. Considerar el problema de l'edat del capità com un problema absurd és més aviat un judici emès sense tenir en compte el seu origen.

Un altre exemple per reflexionar sobre la contextualització dels problemes ens transporta a la història de la matemàtica xinesa: El Sunzi Suanjing és un text d'aritmètica, l'autor del qual i la data en què es va escriure són desconeguts. El primer capítol comença amb una descripció dels sistemes de mesura de longituds, pesos i capacitats, i continua, amb una breu presentació amb caràcters xinesos, per referir-se a les potències de deu. Els capítols següents fan referència al càlcul amb fraccions, proporcions per al càlcul d'àrees i fraccions i el conegut, a l'àmbit de les matemàtiques superiors, com a "teorema dels residus xinesos", que es pot trobar en molts textos medievals i que actualment s'estudia a les nostres facultats de matemàtiques. Resulta significatiu que a la mateixa obra hi aparegui el següent problema: Una dona de 29 anys ha complert el seu novè mes d'embaràs. Quin és el sexe del futur nadó?

Al text s'hi inclou la resposta -home- i el mètode de resolució s'explica així: S'agafa el 49, s'hi afegeix el període de gestació i s'hi resta l'edat de la dona. Del resultat es resta: 1, el número del cel; 2 , el de la terra; 3 , 


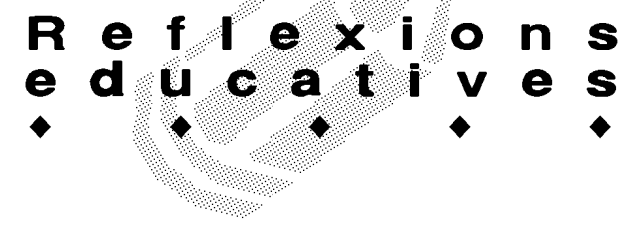

el de l'home; 4, el de les quatre estacions de l'any; 5, les cinc fases; 6 , els sis tons de la flauta; 7 , les set estrelles de l'óssa major; 8, els vuit vents, i 9, els nou territoris de la Xina durant el mandat de Yu el Gran. Si el resultat és senar, el nen serà mascle; si és parell, una femella.

Cal aclarir que la resposta és "home", perquè després de restar el 7 s'obté 1 . El 8 i el 9 no es poden restar, ja que els números negatius "no existeixen" en el context històric en el qual es planteja el problema.

Qualsevol de nosaltres consideraria que la situació plantejada és absurda, ja que no és coherent amb la nostra concepció de la racionalitat i del coneixement científic. No obstant això, no significa que necessàriament hagi de ser absurda en el context històric i cultural en el qual es plantejà, immers en les antigues tradicions mèdiques i numerològiques xineses.

La conclusió que hauria de treure un mestre d'aquest tipus d'exemples no és, de cap manera, que "tot hi cap" quan parlem de matemàtiques, i que proposar als nens i nenes problemes d'aquest tipus sigui adient per a la seva formació matemàtica, fins i tot en el supòsit que els aclarim en quin context es van plantejar. La idea que volem transmetre és que les activitats que qualsevol mestre o mestra porta a terme amb els seus alumnes està en estreta relació amb la seva imatge personal, més o menys elaborada, de què són les matemàtiques, i si aquesta imatge és pobra, o el seu coneixement sobre la matèria és minso, la formació que oferirà als seus alumnes difícilment serà de qualitat. Dedicar un temps a reflexionar i a aprendre sobre la història i la naturalesa d'aquesta ciència li pot ser d'utilitat a l'hora de fer una bona crítica dels materials que li ofereixen les

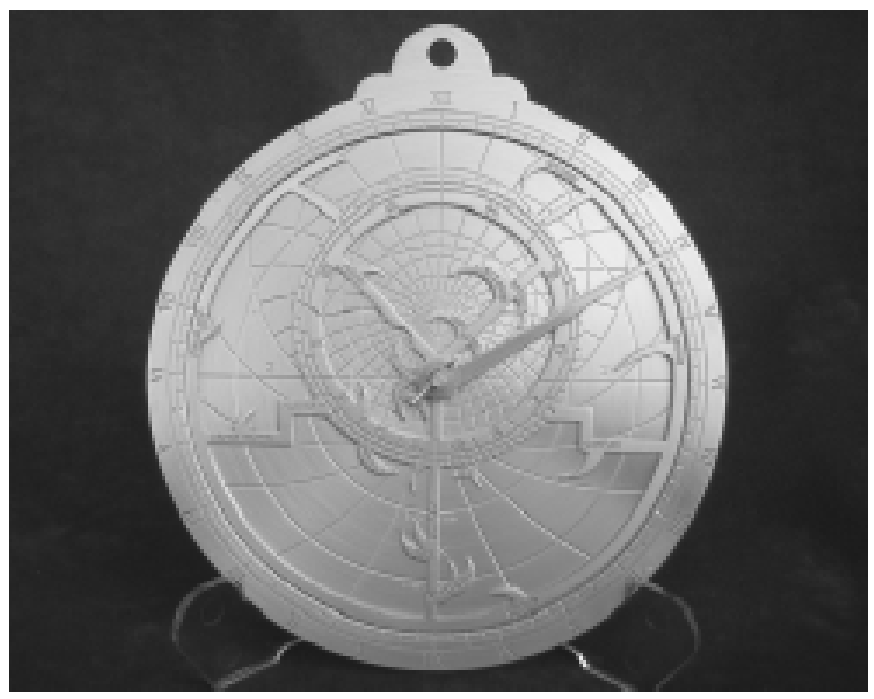

Astrolabi editorials, per tal de seleccionar i donar coherència al problemes i exercicis que planteja, i per mostrar seguretat davant els alumnes quan aquests pregunten: "I això que fem, per a què serveix? El coneixement de la història genera un espai idoni per a la reflexió al voltant de les pròpies idees que un té sobre les matemàtiques i la ciència en general, per qüestionar-les, per impulsar eventuals canvis o per fer-los guanyar fermesa i coherència.

\section{Quin nivell de matemàtiques ha de tenir un mestre?}

És força habitual que els estudiants de magisteri defensin que el que necessiten no és aprendre matemàtiques sinó aprendre a ensenyar-les. Per descomptat que és necessari que coneguin el currículum de l'ensenyament infantil i primari, les dificultats que poden tenir els seus alumnes en l'aprenentatge de les operacions i conceptes elementals i un bon conjunt de problemes i exercicis a punt d'usar-los; però amb això no n'hi ha prou. És sorprenent la quantitat de problemes interessants per a l'escola primària que els futurs mestres rebutgen, perquè els consideren de difícil resolució per als nens, ja que ells -futurs mestres- no els saben resoldre de forma immediata, no veuen de forma clara la manera "d'atacar-los" o no es veuen amb cor d'analitzar-los en detall. Moltes vegades es tracta, únicament, d'una carència de perspectiva per part del futur mestre i no de manca de maduresa en el raonament dels nens i nenes. Analitzem el següent exemple.

En el context d'una prova d'avaluació sobre la competència matemàtica de nens i nenes en edat escolar, es demanà a un grup de mestres que valoressin el següent problema per plantejar-lo a nens de 10 anys: La Marta surt de casa i recorre 2 quilòmetres fins a arribar a l'escola. El Víctor surt de casa i recorre 6 quilòmetres abans no arriba a l'escola. Quants quilòmetres separen les cases de la Marta i del Víctor?

Un percentatge molt alt de mestres respongueren immediatament que el problema no era adient perquè no estava ben formulat, ja que admetia diverses solucions. Efectivament, la solució del problema no és única; però això no li resta interès. Més aviat al contrari. Explorar la situació que planteja el problema va molt més enllà d'un càlcul concret i exigeix un important exercici de representació i generalització al considerar tots els punts del pla situats en dues circumferències concèntriques. Molts alumnes tindran el repte de representar la situació damunt un plànol de dues dimensions i, en qualsevol cas, amb el problema d'explorar diferents situacions, de generalitzar i argumentar de manera rigorosa quines són totes les solucions possibles.

Quan es valora una activitat de matemàtiques de cara a la seva utilització didàctica, no s'ha de perdre de 


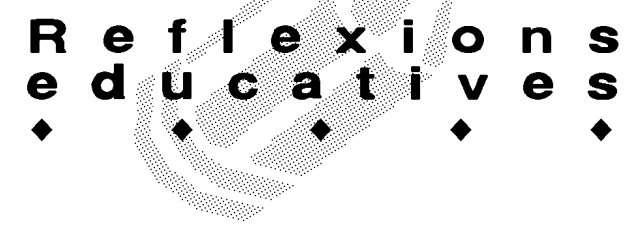

vista que aquesta activitat ha de potenciar elements fonamentals de la resolució de problemes, com l'exploració i la visualització, la formulació de conjectures, la generalització o l'argumentació lògica. Tot això va molt més enllà del coneixement d'algunes tècniques, algorismes i vocabulari matemàtic bàsic. Formar mestres que siguin capaços de dur a terme tasques crítiques de valoració i avaluació és, sens dubte, el gran repte que actualment planteja l'organització dels seus estudis universitaris de matemàtiques, i requereix una oferta basada en l'anàlisi de pràctiques d'aula i de materials concrets, així com d'un coneixement adient dels continguts propis de la ciència i de la seva història.

\section{El valor de la història}

Fins aquí hem esmentat en diverses ocasions de manera general el nostre interès per suggerir una aproximació històrica a una bona part dels continguts de matemàtiques dels actuals programes de magisteri. Aprofundim una mica més en aquesta idea i en la nostra concepció al voltant de com pot utilitzar-se la història amb aquesta finalitat. Utilitzarem exemples relacionats amb la mesura per expressar el que volem transmetre, entre altres motius per la seva especial riquesa per a comprendre l'evolució popular de l'activitat matemàtica, lligada a les inquietuds, la forma de vida d'homes i dones, les institucions o la construcció de les ciències. Al fet de mesurar se li ha prestat poca atenció des de diferents disciplines, i permet rastrejar característiques externes a la mateixa ciència que influeixen en el seu desenvolupament i mètodes, al mateix temps que convoca una gran quantitat d'elements de reflexió filosòfica. La mesura va tenir un rol indiscutible en la transformació del saber científic occidental entre els segles XIII i XVII, i malgrat que en aquest breu article no tindrem la possibilitat d'atendre tots aquests aspectes, val la pena, almenys, deixar-ne constància. Per altra banda, la mesura s'ha considerat com un dels grans blocs de continguts que configuren el currículum de l'educació infantil i primària, i ofereix un bon escenari per a lligar conceptes de la matemàtica elemental des d'un punt de vista aritmètic i geomètric, de manera que l'aprofitarem per apuntar algunes conclusions de caràcter didàctic.

A la nostra cultura s'acostuma a associar la mesura amb una acció de tipus instrumental: s'usen regles, cintes mètriques o balances per controlar, a través dels nombres, qualitats variables del món físic com longitud, pes, volum, velocitat, temperatura, etc. Darrere l'esforç de molts segles d'estudi i d'autèntics instruments d'enginyeria, s'aconseguiren mesurar aquestes magnituds (sempre numèricament), i s'obriren així noves possibilitats per a la física matemàtica. Antigues civilitzacions assoliren importants triomfs intel-lectuals observant i manipulant mesures, i aquests mateixos avenços serien criticats, segles després, en defensa d'una matemàtica pura, en la qual la teoria i la pràctica quedarà totalment diferenciada. Aquesta tensió entre una matemàtica pura, existent només a l'espai abstracte de les idees, i una matemàtica al servei de la natura i de les seves aplicacions quotidianes és a la gènesi de la nostra concepció sobre què són i per a què serveixen les matemàtiques. Existeix una diferència important entre el que es considera mesurar com a activitat quotidiana i pràctica -molt difosa a l'escola, però l'interès de la qual s'esgota de seguida des d'un punt de vista matemàtic més avançati el desenvolupament de la matemàtica al voltant d'importants problemes històrics relacionats amb la mesura, com per exemple el problema de la incommensurabilitat, la quadratura del cercle o el càlcul d'àrees i volums. Conèixer aquesta relació entre matemàtiques i mesura a través de problemes i relats històrics pot convertir-se en una experiència cultural realment gratificant, amb influència indiscutible per a la formació integral d'un mestre, no necessàriament per repetir-los de nou davant els nens i nenes, sinó per reelaborar de manera coherent la pràctica a l'aula sobre les activitats matemàtiques més elementals. Analitzarem, novament mitjançant un exemple, quina és la idea que volem transmetre.

\section{La primera gran crisi de la matemàtica: les quantitats incommesurables}

Ja que la idea de mesura d'una magnitud generalment s'associa amb la d'assignar un nombre a partir d'una unitat utilitzant l'instrument de mesura adient, l'existència de magnituds "que no poden mesurar-se" sembla anar en contra de la intuïció. Per exemple, pot resultar evident en un primer moment que, donat un segment qualsevol, és possible expressar quant mesura mitjançant un nombre enter o mitjançant una fracció de la unitat de longitud que es vulgui, de manera que es podrà fer servir un nombre decimal. En el pitjor dels casos -es pensaria- aquesta fracció pot ser igual a un decimal periòdic, com $1 / 3$, i s'hauria de fer un exercici d'aproximació. No obstant això, la realitat és molt diferent matemàticament parlant, i l'existència de segments que no podien mesurar-se a partir d'altres provocà una gran crisi en la matemàtica de l'antiguitat, perquè significava que, en general, no era possible trobar un nombre que expressés la mesura exacta d'un segment prenent-ne un altre com a unitat. Però com comprendre que un descobriment com aquest pugui generar una crisi intel.lectual? La diferència entre magnitud, unitat de mesura i raó de proporcionalitat, així com un correcte coneixement del que són els nombres racionals i irracionals és 


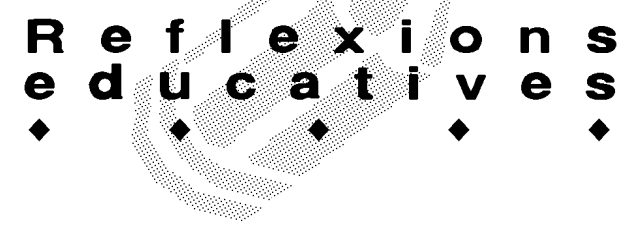

fonamental per poder analitzar adequadament la situació. Sovint es dóna per suposat que qualsevol mestre té suficientment clars aquests conceptes quan estudia un tema de mesura amb els seus alumnes. Si això és així o no, el millor és que cada u ho jutgi d'acord amb la seva experiència. Ara aclarirem amb una mica més de detall l'exemple que acabem de plantejar, i per a això farem una petita incursió en la història de la matemàtica, concretament en el context de la matemàtica de l'escola pitagòrica.

Pitàgores fou contemporani, per exemple, de Buda, de Confuci i de Lao-Tse, de manera que no és absurd afirmar que durant els seus llargs viatges és molt probable que assimilés no només coneixements matemàtics, sinó també religiosos, en un moment històric que fou crucial per al desenvolupament del pensament religiós i científic. Pitàgores concedia a les matemàtiques un paper insubstituïble per assolir un estat de perfecció espiritual, i una de les màximes més importants de la seva escola era que els nombres ho eren tot i que res no es podia concebre sense ells. Fins aleshores, la majoria dels coneixements sobre aritmètica s'usaven en la resolució de problemes quotidians concrets, amb poca o nul.la discussió al voltant de la seva lògica i filosofia. Contràriament, aquest tipus de coneixement pràctic no interessava especialment els seguidors de Pitàgores, profundament preocupats per un tipus d'activitat que es guiava pel més pur desig de saviesa i misticisme. Els pitagòrics utilitzaven un sistema de numeració que els permetia expressar qualsevol mesura de longitud mitjançant nombres enters o fraccionaris. Però les seves investigacions els costaren un terrible disgust quan es trobaren amb un cas particular de l'avui conegut com a teorema de Pitàgores. L'exemple més antic de què disposem sobre la utilització pràctica d'aquest teorema és molt anterior a Pitàgores i procedeix de Babilònia; també s'han trobat referències anteriors a l'escola pitagòrica en obres egípcies, índies i xineses. Existeixen dues tradicions en la utilització d'aquest teorema, que es poden diferenciar fàcilment. La primera és algebraica, i afirma que la hipotenusa d'un triangle rectangle és l'arrel quadrada de la suma dels quadrats dels altres dos costats; la segona és constructiva o geomètrica i afirma que la superfície del quadrat construït damunt la diagonal d'un rectangle és igual a la suma de les superfícies respectives de dos quadrats construïts damunt els seus costats. La primera acostuma a associar-se a una tradició oriental en les matemàtiques d'antigues civilitzacions, i la segona a la tradició grega.

Considerem el cas particular del teorema per a un triangle rectangle els catets del qual mesuren 1. Una senzilla comprovació visual ens assegura que l'àrea de qualsevol dels quadrats construïts damunt els dos catets és exactament la meitat de l'àrea del quadrat construït damunt la hipotenusa (vegeu la figura 1). És evident que la longitud de la hipotenusa no pot ser un múltiple enter del catet, perquè encara que sigui més gran no arriba a ser el doble. Per tant, si només coneguéssim els nombres enters i els racionals, és evident que esperaríem trobar una fracció que ens permetés mesurar la hipotenusa d'aquell triangle.

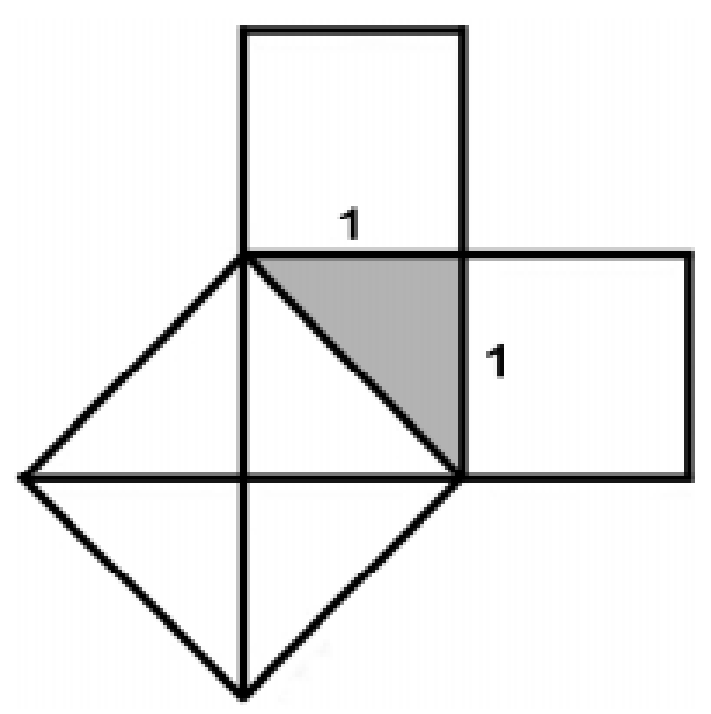

Figura 1: Cas particular del teorema de Pitàgores

Actualment sabem que existeixen nombres que no poden escriure's com una fracció, però malgrat això els podem associar a la mesura d'una longitud. Aquest és el cas del número $\sqrt{ } 2$, que és, precisament, el que mesura la longitud de la hipotenusa en l'exemple de la figura 1 . El número $\sqrt{ } 2$ és ubicat en algun lloc entre 1 i 3/2. Si volguéssim ser més exactes, podríem dir que és entre $7 / 5$ i $3 / 2$; i podríem seguir acotant els extrems racionals de l'interval en el qual es troba, tant com volguéssim, però sense poder obtenir mai el seu valor decimal exacte. El cas de $\sqrt{2}$ no és excepcional; existeixen infinits nombres amb aquesta propietat, que són els que es denominen irracionals.

Així, els pitagòrics es trobaren amb un segment la mesura del qual no era possible expressar-la mitjançant els nombres que coneixien. Si es pensa que per a ells els nombres eren l'essència de totes les coses, és fàcil comprendre que el descobriment els causà una enorme consternació. Denominaren aquestes quantitats amb el terme incommensurables, i a partir d'aquell moment optaren per oblidar-se dels nombres per resoldre problemes geomètrics i es referiren a les mesures en termes 


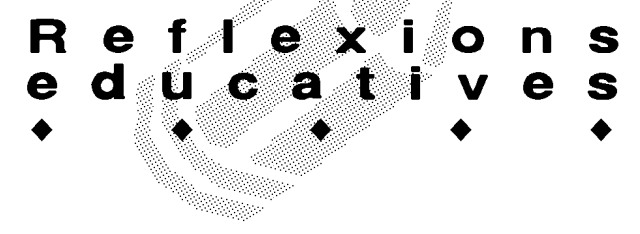

de proporcions entre segments de longituds enteres ( $\mathrm{i}$ anàlogament en el cas d'àrees i de volums). Així doncs, l'escàndol de les quantitats incommensurables imposà un canvi de rumb en les investigacions matemàtiques de l'antiguitat, transformant en geomètriques les consideracions aritmètiques de què tant s'havien ocupat. $A$ diferència dels pitagòrics, nosaltres tenim l'avantatge de disposar de tots els nombres, i per tant podem considerar qualsevol distància com a mesurable. Això, sumat al fet que en la majoria dels exercicis escolars on intervenen mesures es considera suficient una bona aproximació decimal, sense reflexionar gaire sobre la precisió del resultat, fa que la idea de semblança de figures per a la comprensió del concepte matemàtic de longitud o d'àrea es perdi en la majoria dels problemes pràctics que tracten del seu càlcul. El resultat final de tot aquest aglomerat de conceptes matemàtics als quals no se'ls dóna la connexió adequada, present en aquest $i$ en altres molts exemples, és una imatge confusa i distorsionada de la matemàtica, molt allunyada de la fortalesa i coherència lògica que la caracteritza.

\section{L'important rol dels futurs mestres}

D'una tesi del tipus "les matemàtiques que s'han d'aprendre a l'escola han de preparar l'estudiant per a la seva vida quotidiana" es pot desprendre, de manera superficial, que no és tan important aprendre, per exemple, què són els nombres irracionals. És veritat que pocs ciutadans es trobaran en el seu dia a dia amb l'arrel quadrada de 2 , i en el pitjor dels casos serà suficient que agafin la calculadora, regle o metre de costura o de fuster, i siguin capaços d'aproximar-la correctament al nombre decimal corresponent. Però el cert és que l'aprenentatge de conceptes complexos de la matemàtica ha d'anar necessàriament associat a un exercici indiscutible de raonament que inclogui posar en discussió el seu significat i la seva raó de ser. No es tracta que l'escola formi ciutadans que puguin valer-se en un món que altres ja han construït per a ells, sinó que formi ciutadans que transformin i reconstrueixin la realitat en la qual viuen, i només seran capaços de fer-ho en la mesura que disposin de les eines adequades. Es podria parlar a bastament sobre les possibilitats que ofereix la matemàtica -no necessàriament concebuda tal i com s'ensenya actualment a moltes escoles- per contribuir a aquesta finalitat.

Naturalment un pot creure's a ulls clucs el que s'ha dit fins aquí i repetir un discurs que advoqui per una imatge més complexa de la matemàtica que aquella a la qual en general estem habituats, però el cert és que interioritzar aquesta imatge requereix, sobretot, temps per a resoldre problemes, per a conèixer la seva gènesi i el seu desenvolupament i per a reflexionar sobre la seva naturalesa. És important que els futurs mestres percebin que en aquesta matemàtica que ensenyaran als seus alumnes hi ha involucrades idees molt sofisticades (nombres naturals, sistemes de numeració, etc.) al voltant de les quals cal treballar, i que aprofitin la imaginació i la creativitat -la seva i la dels seus alumnesper oferir situacions en què pensar es converteixi en un joc agradable. Això resultarà difícil si únicament es busca la connexió de les matemàtiques amb experiències quotidianes, com anar a comprar, organitzar l'espai dels jocs, etc. Problemes interessants i absolutament significatius poden sorgir en situacions de jocs de taula $i$ d'estratègia, o a l'intentar raonar per què no existeixen plantes com les que apareixen en el conte Juan y las habichuelas mágicas o monstres com King Kong, a l'aproximar quina hauria de ser la longitud d'una filera feta amb tots els habitants de la Terra i preguntar-se si arribaria fins a la lluna o al voler idear maneres diferents de lligar-se els cordons de les sabates i trobar una forma òptima d'ordenar-los sistemàticament. Les biblioteques són plenes de fonts que fan referència a continguts matemàtics i reflexions didàctiques al seu voltant; internet, també; de tant en tant hi ha conferències interessants sobre matemàtiques, i moltes associacions de pro-

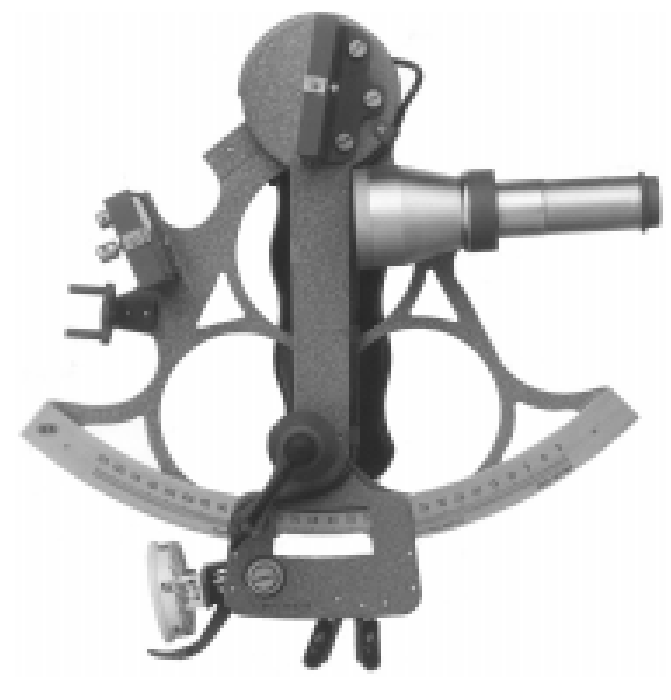

Sextant

fessors ofereixen, a les seves publicacions i activitats, excel-lents complements per a l'experiència diària a les aules. El realment interessant és voler, poder i saber accedir als recursos existents, disposar de bones estratègies de selecció i ser capaç de valorar-les críticament. 